\title{
Serum levels of vitamin D, parathyroid hormone and calcium in relation to survival following breast cancer
}

\author{
Linnea Huss $\cdot$ Salma Butt $\cdot$ Signe Borgquist $\cdot$ \\ Martin Almquist $\cdot$ Johan Malm $\cdot$ Jonas Manjer
}

Received: 3 January 2014 / Accepted: 5 June 2014/Published online: 22 June 2014

(C) The Author(s) 2014. This article is published with open access at Springerlink.com

\begin{abstract}
Purpose Vitamin D, parathyroid hormone (PTH) and calcium in blood are correlated with each other. Previous studies have suggested vitamin D to have anti-proliferative effects on tumor cells, whereas PTH may have carcinogenic effects. A cancer disease may influence calcium levels in blood, but less is known about calcium and its potential effect on cancer risk and survival. The aim of this study was to examine pre-diagnostic levels of vitamin D (25OHD), PTH and calcium in relation to survival after breast cancer.

Methods The Malmö Diet and Cancer Study enrolled 17,035 women between 1991 and 1996. 672 patients developed incident invasive breast cancer up until 31 December
\end{abstract}

L. Huss $(\bowtie) \cdot$ S. Butt $\cdot$ J. Manjer

Department of Surgery, Skåne University Hospital, Lund

University, 20502 Malmö, Sweden

e-mail: Linnea.Huss@med.lu.se

\section{S. Borgquist}

Department of Oncology, Skåne University Hospital, Lund, Sweden

\section{S. Borgquist}

Division of Oncology, Department of Clinical Sciences, Lund

University, Lund, Sweden

\section{Almquist}

Department of Surgery, Skåne University Hospital, Lund

University, Lund, Sweden

\section{J. Malm}

Section for Clinical Chemistry, Department of Laboratory

Medicine, Skåne University Hospital, Lund University, Malmö,

Sweden

J. Manjer

Department of Plastic Surgery, Skåne University Hospital, Lund

University, Malmö, Sweden
2006. Serum samples collected at baseline were analyzed for 25OHD, PTH and calcium. All patients were followed until 31 December 2010 using the Swedish Cause of Death Registry. The analytes were divided into tertiles and the risk of death from breast cancer was analyzed using an adjusted Cox proportional hazards analysis, yielding hazard ratios with $95 \%$ confidence intervals.

Results Levels of 25OHD and breast cancer mortality were associated in a u-shaped manner with the highest mortality among patients in the first (2.46: 1.38-4.37) and third tertiles (1.99: 1.14-3.49), as compared to the second. An inverse relation was found between calcium levels and breast cancer mortality, with the lowest mortality in the third tertile, (0.53: 0.30-0.92) as compared to the first. There was no clear association between PTH and breast cancer mortality.

Conclusions This study shows that pre-diagnostic 25OHD and calcium may affect survival following breast cancer.

Keywords Breast cancer - Calcium - Mortality - PTH · Survival · Vitamin D

\section{Introduction}

Vitamin D has been suggested to have anti-proliferative effects on breast tumor cells in animal and in vitro studies [1]. Ecological studies have shown a difference in breast cancer incidence and survival related to geography, suggesting a beneficial effect of vitamin D levels due to solar exposure [24] and others have shown a better survival in patients diagnosed with breast cancer during summer and autumn $[5,6]$.

Several prospective epidemiological studies have investigated the relationship between vitamin $\mathrm{D}$ and breast cancer incidence, but with conflicting results [1, 7-9]. A 
recent meta-analysis of studies which had measured vitamin D levels (25OHD in serum or plasma) close to diagnosis in early stage breast cancer, found an association between low levels of vitamin D and a high mortality, i.e., a poor survival [10]. Only one study has previously investigated pre-diagnostic serum levels of vitamin D in relation to breast cancer mortality among breast cancer patients. Freedman et al. [11] found an inverse relationship between low pre-diagnostic levels of vitamin D (25OHD) and high breast cancer mortality.

Levels of vitamin D and parathyroid hormone (PTH) are inversely correlated with each other [12], and both influence the level of calcium in blood. PTH is secreted from the parathyroid gland when calcium levels are low and stimulates release of calcium from bone into blood and synthesis of active vitamin $\mathrm{D}\left(1,25(\mathrm{OH})_{2} \mathrm{D}\right)$ from its storage form (25OHD). It has been suggested in experimental studies that PTH has a carcinogenic and tumor promoting effect [13-16], and it has also been indicated that primary hyperparathyroidism may increase the risk of breast cancer [17-20]. To our knowledge, no previous study has investigated the relationship between levels of PTH and breast cancer survival.

It is well known that calcium levels may be increased following different cancer forms. One previous study has shown an increased incidence of breast cancer with high pre-diagnostic calcium levels [21]. It is, however, unknown what impact pre-diagnostic calcium levels may have on breast cancer survival. Since calcium has been shown to be an important intracellular messenger, involved in proliferation, apoptosis and cell signaling [22], it is possible to hypothesize that calcium may affect survival following breast cancer.

In 1991, inclusion in a population-based prospective cohort study began in Malmö, creating The Malmö Diet and Cancer Study (MDCS), including 17,035 women. Blood samples taken at baseline are now available for analysis.

Our main hypothesis is that low vitamin D (25OHD) is associated with a poor survival following breast cancer, i.e., a high mortality among cases. Our secondary hypothesis is that high pre-diagnostic PTH is also associated with a poor survival. As a third explorative analysis, we investigated if calcium also had an effect on survival.

\section{Materials and methods}

The Malmö Diet and Cancer Study (MDCS)

Between 1991 and 1996, all residents in the Southern Swedish city of Malmö, born 1923-1950, were invited to participate in a population-based prospective cohort study.
A total of $41 \%$ of eligible subjects participated and 17,035 women completed the baseline examination [23]. Written informed consent was obtained from all participants. Baseline examination included a dietary assessment and a self-administered questionnaire on different life-style factors. Moreover, a trained nurse performed anthropometric measurements and blood samples were drawn. Subjects were included, and had their blood samples drawn, evenly over the calendar year, except for less recruitment in December and June, and none in July. The ethical committee in Lund, Sweden, approved the MDCS (LU 51-90), and the present study (Dnr 652/2005 and Dnr 23/2007).

\section{Study population}

For identification of breast cancer cases within the MDCS cohort, The Swedish Cancer Registry was used. Prior to baseline examination, 576 out of the 17,035 women were diagnosed with breast cancer. These women were categorized as prevalent breast cancer cases and therefore excluded from the current analysis. In all, 766 women were diagnosed with breast cancer up until December 31, 2006, but two incident cases had not donated blood at baseline [7]. We found that 77 tumors were cases of ductal cancer in situ, and these cases were excluded as the present study intended to examine survival, i.e., there is a very low mortality, if any, associated with in situ breast cancer. Another 15 cases were excluded due to bilateral cancer, as it was difficult to interpret information about tumor characteristics in these cases. Finally, a total of 672 women with invasive unilateral breast cancer were included in the present analysis. Mean time from baseline examinations to diagnosis was 7.12 years with a standard deviation (SD) of 3.82 .

\section{Clinical information}

Information on type of surgery and planned adjuvant therapy, recommended by a treatment conference immediately following surgery, was retrieved from clinical notes. Some $41 \%$ $(n=272)$ underwent mastectomy, and $57 \%(n=382)$ had a partial mastectomy. Lymph nodes were examined after sentinel node biopsy in $26 \%(n=173)$ and after axillary dissection in $62 \% \quad(n=416)$. Adjuvant treatment with radiotherapy was planned for $54 \%(n=361)$ of patients, endocrine treatment in $46 \%(n=312)$, and $14 \%(n=92)$ were planned for chemotherapy, Table 1.

Histopathological analysis

Information on laterality, tumor size and lymph node metastasis was retrieved from medical records and histopathological reports. All invasive tumors, diagnosed 
Table 1 Vital status in relation to age at baseline

\begin{tabular}{|c|c|c|c|c|}
\hline \multirow[t]{2}{*}{ Factor } & \multicolumn{4}{|l|}{ Survival } \\
\hline & $\begin{array}{l}\begin{array}{l}\text { Alive } \\
(n=517)\end{array} \\
\text { Number (co } \\
\text { Mean (SD) }\end{array}$ & $\begin{array}{l}\text { Dead from } \\
\text { breast } \\
\text { cancer } \\
(n=101) \\
\text { lumn percent }) \\
\text { in italics }\end{array}$ & $\begin{array}{l}\text { Dead from } \\
\text { other cause } \\
(n=54)\end{array}$ & $\begin{array}{l}\text { Total } \\
(n=672)\end{array}$ \\
\hline $\begin{array}{l}\text { Age at } \\
\text { baseline }\end{array}$ & $56.3(6.8)$ & $58.3(8.0)$ & $61.8(6.8)$ & $57.0(7.2)$ \\
\hline $\begin{array}{l}\text { Age at } \\
\text { diagnosis }\end{array}$ & $63.7(7.6)$ & $64.6(8.9)$ & $67.8(7.4)$ & $64.2(7.9)$ \\
\hline \multicolumn{5}{|l|}{ Size } \\
\hline $1-10 \mathrm{~mm}$ & $159(30.8)$ & $3(3.0)$ & $17(31.5)$ & $179(26.6)$ \\
\hline $11-20 \mathrm{~mm}$ & $240(46.6)$ & $38(37.6)$ & $18(33.3)$ & $297(44.2)$ \\
\hline$\geq 21 \mathrm{~mm}$ & $110(21.5)$ & $52(51.5)$ & $18(33.3)$ & $181(26.9)$ \\
\hline Unknown & $6(1.2)$ & $8(7.9)$ & $1(1.9)$ & $15(2.2)$ \\
\hline \multicolumn{5}{|l|}{$\begin{array}{l}\text { Lymph node } \\
\text { status }\end{array}$} \\
\hline Positive & $128(25.1)$ & $63(62.4)$ & $11(20.4)$ & $204(30.4)$ \\
\hline Negative & $384(74.3)$ & $36(35.6)$ & $42(77.8)$ & $462(68.8)$ \\
\hline Unknown & $3(0.6)$ & $2(2.0)$ & $1(1.9)$ & $6(0.9)$ \\
\hline \multicolumn{5}{|l|}{$\begin{array}{l}\text { Distant } \\
\text { metastasis }\end{array}$} \\
\hline Yes & $0(0.0)$ & $9(8.9)$ & $0(0.0)$ & $9(1.3)$ \\
\hline No & $514(99.8)$ & $91(90.1)$ & $54(100.0)$ & $661(98.4)$ \\
\hline Unknown & $1(0.2)$ & $1(1.0)$ & $0(0.0)$ & $2(0.3)$ \\
\hline \multicolumn{5}{|l|}{$\begin{array}{l}\text { Nottingham } \\
\text { grade }\end{array}$} \\
\hline I & $150(29.1)$ & $8(7.9)$ & $16(29.6)$ & $175(26.0)$ \\
\hline II & $244(47.4)$ & $31(30.7)$ & $20(37.0)$ & $296(44.0)$ \\
\hline III & $90(17.5)$ & $48(47.5)$ & $14(25.9)$ & $152(22.6)$ \\
\hline Unknown & $31(6.0)$ & $14(13.9)$ & $4(7.4)$ & $49(7.3)$ \\
\hline \multicolumn{5}{|l|}{$\begin{array}{l}\text { Histological } \\
\text { type }\end{array}$} \\
\hline Ductal & 345 (66.9) & $66(65.3)$ & $33(61.1)$ & $445(66.2)$ \\
\hline Lobular & $96(18.8)$ & $21(20.8)$ & 9 (16.7) & 127 (18.9) \\
\hline $\begin{array}{l}\text { Other/ } \\
\text { mixed }\end{array}$ & $47(9.1)$ & $2(2.0)$ & 9 (16.7) & $58(8.6)$ \\
\hline Unknown & $27(5.2)$ & 12 (11.9) & $3(5.6)$ & $42(6.2)$ \\
\hline \multicolumn{5}{|l|}{ ER } \\
\hline $\begin{array}{c}0-10 \% \\
\text { pos }\end{array}$ & $47(9.1)$ & $18(17.8)$ & $6(11.1)$ & 71 (10.6) \\
\hline$>10 \%$ pos & $380(73.9)$ & $63(62.4)$ & $43(79.6)$ & 488 (72.6) \\
\hline Unknown & $88(17.0)$ & $20(19.8)$ & $5(9.3)$ & $113(16.8)$ \\
\hline \multicolumn{5}{|l|}{$\mathrm{PgR}$} \\
\hline $\begin{array}{c}0-10 \% \\
\text { pos }\end{array}$ & $183(35.4)$ & $50(49.5)$ & $28(51.9)$ & $261(38.8)$ \\
\hline$>10 \%$ pos & 195 (37.9) & $24(23.8)$ & $16(29.6)$ & $236(35.1)$ \\
\hline Unknown & 137 (26.7) & $27(26.7)$ & $10(18.5)$ & $175(26.0)$ \\
\hline
\end{tabular}

Age at diagnosis and prognostic factors for breast cancer between 1991 and 2004, were pathologically re-evaluated by one senior pathologist. The re-evaluation concerned tumor invasiveness, tumor type according to WHO and grading according to Elston-Ellis [24, 25]. Tumors diagnosed between 2005 and 2006 were classified according to WHO type and Elston-Ellis grade at diagnosis, thus information was readily available from clinical notes and pathology reports. Estrogen receptor status (ER) and progesterone receptor status $(\mathrm{PgR})$ on all tumors were evaluated with tissue microarray technique (TMA), using immunohistochemical (IHC) analysis with specific antibodies as described in detail previously [25]. In line with Swedish clinical practice, the cutoff points for dichotomizing tumors, as being negative or positive, were 0-10 and $11-100 \%$ positive nuclei, respectively.

\section{Laboratory analysis}

At baseline examination, serum was extracted within $1 \mathrm{~h}$ from venipuncture and samples were thereafter stored at $-80{ }^{\circ} \mathrm{C}$ [26]. Serum from identified cases of breast cancer was retrieved from the MDCS bio bank and analyzed for 25OHD, PTH and calcium. The samples had not been previously thawed. High-pressure liquid chromatography (HPLC) was used to analyze $25 \mathrm{OHD}_{3}$, and laboratory analysis was successful in 655 out of 672 cases in the present study population. PTH was analyzed with the Immunolite $^{\circledR} 2000$ Intact PTH immunoassay (Diagnostic Products corporation, Los Angeles, CA), 664 successful analyses. Total calcium was successfully analyzed in 661 cases by neutral carrier ion-selective electrode [27]. Unsuccessful analyses were due to inadequate volume or quality of sera. The analysis of blood samples was performed during 2007 as part of a previous case-control study and has previously been described in detail [7].

\section{Endpoint retrieval}

The Swedish Cause of Death Registry was used to identify cases that had deceased as well as their cause and date of death. End of follow-up was the date of death, date of emigration or December 31, 2010. Mean time from diagnosis until end of follow-up was 8.7 years (SD: 4.0). Subsequently, the women were divided into three different groups: (1) women still alive at end of follow-up; (2) women with breast cancer as cause of death or with breast cancer as a contributing cause of death which were classified as "dead from breast cancer," i.e., "breast cancerspecific mortality"; and (3) women deceased from causes unrelated to breast cancer ("dead from other cause"). 
Table 2 Vital status in relation to treatment

\begin{tabular}{|c|c|c|c|c|}
\hline \multirow[t]{2}{*}{ Factor } & \multicolumn{4}{|l|}{ Vital status } \\
\hline & $\begin{array}{l}\text { Alive }(n=517) \\
\text { Column percent }\end{array}$ & $\begin{array}{l}\text { Dead breast } \\
\text { cancer }(n=101)\end{array}$ & $\begin{array}{l}\text { Dead other } \\
\text { cause }(n=54)\end{array}$ & $\begin{array}{l}\text { Total } \\
(n=672)\end{array}$ \\
\hline \multicolumn{5}{|l|}{ Surgical treatment } \\
\hline Mastectomy & 36.6 & 60.4 & 40.7 & 40.5 \\
\hline Partial mastectomy & 61.7 & 31.7 & 57.4 & 56.8 \\
\hline Local excision or surgical biopsy & 0.4 & 0.0 & 0.0 & 0.3 \\
\hline Unknown & 1.4 & 7.9 & 1.9 & 2.4 \\
\hline \multicolumn{5}{|l|}{ Axillary surgery } \\
\hline No axillary dissection & 9.9 & 5.9 & 20.4 & 10.1 \\
\hline Axillary dissection & 58.6 & 75.2 & 68.5 & 61.9 \\
\hline Sentinel node biopsy & 29.8 & 13.9 & 9.3 & 25.7 \\
\hline Singular node biopsy & 0.4 & 0.0 & 0.0 & 0.3 \\
\hline Unknown & 1.4 & 5.0 & 1.9 & 1.9 \\
\hline \multicolumn{5}{|l|}{ Planned adjuvant radiotherapy } \\
\hline No & 36.0 & 35.6 & 53.7 & 37.4 \\
\hline Yes & 53.4 & 61.4 & 42.6 & 53.7 \\
\hline Unknown & 10.6 & 3.0 & 3.7 & 8.9 \\
\hline \multicolumn{5}{|l|}{ Planned adjuvant endocrine therapy } \\
\hline No & 51.5 & 43.6 & 63.0 & 51.2 \\
\hline Yes & 48.5 & 56.5 & 37.1 & 48.8 \\
\hline Anti-estrogen & 37.9 & 43.6 & 29.6 & 38.1 \\
\hline Aromatase inhibitor & 3.5 & 7.9 & 1.9 & 4.0 \\
\hline Other/unknown drug & 4.6 & 2.0 & 5.6 & 4.3 \\
\hline Unknown & 2.5 & 3.0 & 0.0 & 2.4 \\
\hline \multicolumn{5}{|l|}{ Planned adjuvant chemotherapy } \\
\hline No & 78.3 & 63.4 & 90.7 & 77.1 \\
\hline Yes & 10.6 & 33.7 & 5.6 & 13.7 \\
\hline Unknown & 11.0 & 3.0 & 3.7 & 9.2 \\
\hline
\end{tabular}

Statistical methods

Levels of 25OHD, PTH and calcium were divided into tertiles. Survival was assessed as mortality from breast cancer per 100,000 person-years. In order to test differences in mortality between tertiles, a Cox's proportional hazards analysis, yielding hazard ratios (HR) and $95 \%$ confidence intervals (CI), was used. The assumption of proportional hazards was met as tested by log-minus log plots.

The model was subsequently adjusted for factors known to influence levels of $25 \mathrm{OHD}$, PTH and calcium, such as season of blood draw and age at baseline. In order to adjust for storage time, year of baseline examination was included in the model.

The Cox analysis was further adjusted for factors known to affect survival following breast cancer such as age at diagnosis, tumor size, lymph node status, the presence of distant metastases, Nottingham grade, histological type, ER status and PgR status. All confounders were tested one at a time in the model in order to see which factor affected hazard ratio (HR) the most.

As a sensitivity analysis, we adjusted our exposures for each other. As an example, 25OHD was adjusted for the other exposures, PTH and calcium, individually and combined.

To assess the risk of reverse causality, we performed sensitivity analyses, repeating all analyses, excluding women diagnosed with breast cancer within 2 years from the baseline examination ( $n=82)$. Another sensitivity analysis, in which the Cox analyses were also adjusted for different types of adjuvant therapy, was also performed.

Moreover, we made sensitivity analyses in which we stratified the analyses for premenopausal, respectively, postmenopausal women at the time of diagnosis, and for body mass index (BMI) $<25$ (considered normal weight) versus $\mathrm{BMI} \geq 25$ (overweight). 
Table 3 Tertiles of $25 \mathrm{OHD}_{3}, \mathrm{PTH}$ and Ca in relation to breast cancer mortality

\begin{tabular}{|c|c|c|c|c|c|c|c|c|c|}
\hline Analyte & Tertile & Range & $\begin{array}{l}\text { Numbers } \\
\text { within tertile }\end{array}$ & $\begin{array}{l}\text { Person- } \\
\text { years }\end{array}$ & $\begin{array}{l}\text { Dead breast } \\
\text { cancer }\end{array}$ & $\begin{array}{l}\text { Breast cancer } \\
\text { mortality/ } \\
100,000\end{array}$ & $\mathrm{HR}^{\mathrm{a}}$ & $\mathrm{HR}^{\mathrm{b}}$ & $\mathrm{HR}^{\mathrm{c}}$ \\
\hline \multirow[t]{4}{*}{$\begin{array}{l}25 \mathrm{OHD}_{3} \\
(\mathrm{nmol} / \mathrm{L})\end{array}$} & 1 & $\leq 75$ & 221 & 1,879 & 39 & 2,076 & $\begin{array}{l}1.84 \\
\quad(1.08-3.13)\end{array}$ & $\begin{array}{l}2.04 \\
\quad(1.19-3.51)\end{array}$ & $\begin{array}{l}2.46 \\
\quad(1.38-4.37)\end{array}$ \\
\hline & 2 & $76-99$ & 216 & 1,863 & 21 & 1,127 & 1 & 1 & 1 \\
\hline & 3 & $\geq 100$ & 218 & 1,911 & 39 & 2,041 & $\begin{array}{l}1.81 \\
\quad(1.06-3.07)\end{array}$ & $\begin{array}{l}1.78 \\
\quad(1.05-3.04)\end{array}$ & $\begin{array}{l}1.99 \\
\quad(1.14-3.49)\end{array}$ \\
\hline & & & & & & & $p$ trend: 0.95 & $p$ trend: 0.62 & $p$ trend: 0.51 \\
\hline \multirow[t]{4}{*}{$\begin{array}{l}\text { PTH } \\
\quad(\mathrm{pmol} / \mathrm{L})\end{array}$} & 1 & $\leq 2.95$ & 223 & 1,842 & 36 & 1,954 & $\begin{array}{l}1.31 \\
\quad(0.81-2.12)\end{array}$ & $\begin{array}{l}1.32 \\
\quad(0.81-2.14)\end{array}$ & $\begin{array}{l}0.98 \\
\quad(0.53-1.65)\end{array}$ \\
\hline & 2 & $2.96-4.41$ & 220 & 2,000 & 30 & 1,500 & 1 & 1 & 1 \\
\hline & 3 & $\geq 4.42$ & 221 & 1,904 & 34 & 1,786 & $\begin{array}{l}1.20 \\
(0.73-1.96)\end{array}$ & $\begin{array}{l}1.21 \\
\quad(0.74-1.98)\end{array}$ & $\begin{array}{l}0.86 \\
\quad(0.51-1.47)\end{array}$ \\
\hline & & & & & & & $p$ trend: 0.71 & $p$ trend: 0.70 & $p$ trend: 0.62 \\
\hline \multirow{4}{*}{$\begin{array}{l}\text { Calcium } \\
(\mathrm{mmol} / \mathrm{L})\end{array}$} & 1 & $\leq 2.36$ & 235 & 2,067 & 38 & 1,838 & 1 & 1 & 1 \\
\hline & 2 & $2.37-2.43$ & 224 & 1,932 & 33 & 1,707 & $\begin{array}{l}0.93 \\
\quad(0.58-1.48)\end{array}$ & $\begin{array}{l}0.90 \\
\quad(0.56-1.44)\end{array}$ & $\begin{array}{l}0.80 \\
\quad(0.48-1.34)\end{array}$ \\
\hline & 3 & $\geq 2.44$ & 202 & 1,727 & 28 & 1,622 & $\begin{array}{l}0.88 \\
\quad(0.54-1.44)\end{array}$ & $\begin{array}{l}0.82 \\
\quad(0.50-1.34)\end{array}$ & $\begin{array}{l}0.53 \\
\quad(0.30-0.92)\end{array}$ \\
\hline & & & & & & & $p$ trend: 0.61 & $p$ trend: 0.40 & $p$ trend: 0.02 \\
\hline
\end{tabular}

a Crude analysis

b Adjusted for season and year of blood sample, and age at baseline

${ }^{c}$ Adjusted for same factors as ${ }^{\mathrm{b}}$ but also for age at diagnosis, size of tumor, Elston-Ellis grade, histological type, ER status, PGR status, lymph node status and distant metastasis at diagnosis

\section{Results}

Out of 672 women, 101 had died due to breast cancer, which gives a breast cancer-specific mortality of 1,738/ 100,000 person-years. A comparison between different outcomes and factors possibly affecting survival is presented in Table 1. Table 2 shows the distribution of treatment in different groups defined the outcome.

There was a statistically significantly higher breast cancerspecific mortality (HR) among patients in the first 1.84 (1.08-3.13) as well as the third 1.81 (1.06-3.07) tertile of 25OHD as compared to the second tertile (Table 3 ). In the adjusted analysis, these associations were strengthened, factors that affected the results most were lymph node status and distant metastasis, and remained statistically significant.

When studying pre-diagnostic levels of PTH, there was also a higher breast cancer-specific mortality among subjects in the first $1.31(0.81-2.12)$ as well as in the third 1.20 (0.73-1.96) tertile (Table 3); however, the results were not statistically significant. Several factors coincided to make the associations disappear in the adjusted analysis, but when adjusting for size of tumor and lymph node status, the reduction was strongest (data not shown).

An inverse relationship was seen between calcium levels and breast cancer-specific mortality, with lower mortality among subjects within the third tertile 0.88 (0.54-1.44).
This association was not statistically significant in the crude analysis, but it was stronger and turned statistically significant $0.53(0.30-0.92)$ when the analysis was adjusted for known prognostic factors (Table 3). Factors adding most to the stronger association were lymph node status and distant metastasis.

In the adjusted analyses, where our studied exposures were adjusted for the other exposures, all results remained the same (data not shown).

In order to exclude women with subclinical breast cancer at the time of baseline blood donation, we repeated analyses excluding women diagnosed with breast cancer within 2 years as a sensitivity analysis. We found similar associations regarding 25OHD in the first tertile (2.22: 1.20-4.11), but statistical significance was lost for the third tertile (1.65: 0.89-3.06). No association could be seen between PTH levels and breast cancer mortality in this analysis. There was still a low mortality from breast cancer among patients with calcium levels within the third tertile in the adjusted analysis, but this association did not reach statistical significance (0.69: 0.37-1.30).

The sensitivity analysis adjusting also for adjuvant therapy showed similar associations in all analyses (data not shown).

Due to statistical instability in the premenopausal group $(n=65)$, the stratified analyses on menopausal status showed inconclusive results. In the postmenopausal group 
$(n=587)$, results were similar in all analyses, though confidence intervals were somewhat widened (data not shown).

In the analyses, where we stratified for BMI, we noticed that results were attenuated in the group with BMI $\geq 25$ $(n=326)$, compared to the group with BMI $<25$ $(n=346)$, though this observation is inconclusive due to low statistical power in the analysis (data not shown).

\section{Discussion}

We found a statistically significant $\mathrm{u}$-shaped relationship, between pre-diagnostic levels of $25 \mathrm{OHD}$ and breast cancerspecific mortality, with higher mortality, i.e., poor survival, among patients with 25OHD levels within the first and third tertiles as compared to the second. There was no association between PTH and breast cancer-specific mortality. Regarding levels of calcium and breast cancer-specific mortality, we saw that patients within the highest tertile had a lower mortality, i.e., a better survival.

\section{Vitamin D and breast cancer}

The finding that low $25 \mathrm{OHD}$ levels were associated with a high breast cancer-specific mortality is in line with our hypothesis. It is now well known that vitamin D inhibits growth of tumorderived cells from breast [28] and promote apoptosis in breast cancer cells [29]. On a molecular level, active vitamin D $\left(1,25(\mathrm{OH})_{2} \mathrm{D}\right)$ has been shown to act as a cancer inhibitor in many other ways, such as enhanced DNA repair, immunomodulation and protection against antioxidants, although there are areas not yet understood [30,31]. These mechanisms may indeed explain the results seen in the present study.

One previous study has shown a better survival for breast-, colon- and prostate cancer patients diagnosed during summer or early fall, which would indicate advantages of adequate vitamin D levels during treatment [6]. It has also been suggested that less favorable outcome for African-American women with breast cancer in the USA is due to lower habitual vitamin D status among these women [32]. Directly measured sufficient levels at diagnosis in early breast cancer have in other studies been shown to improve survival [10, 33-37]. Experimental and epidemiological studies taken together; they are consistent with our finding that lower pre-diagnostic levels of 25OHD are related to poor survival. One study measuring vitamin $\mathrm{D}$ before diagnosis found an inverse relationship between pre-diagnostic levels of vitamin D (25OHD) and breast cancer mortality [11]. When analyzing breast cancer mortality, they choose to stratify 25OHD in two categories with levels $>62.5$ and $\leq 62.5 \mathrm{nmol} / \mathrm{L}$ [11], hence they differ only between high and low 25OHD. This cut point is within our first tertile and is therefore also in line with our results.
To this date, there are no available guidelines regarding adequate 25OHD levels, though the Committee of the Institute of Medicine has recommended $40-50 \mathrm{nmol} /$ liter as a lower acceptable level and that levels above $125 \mathrm{nmol} / \mathrm{L}$ should raise concern among clinicians in North America [38]. These recommended clinical cut points are within the first, respectively, third of our tertiles, and $5.9 \%(n=39)$ of our subjects had levels underneath $50 \mathrm{nmol} / \mathrm{L}, 9.3 \%(n=62)$ above $125 \mathrm{nmol} / \mathrm{L}$.

In addition to the findings that women with low levels of 25OHD had a high mortality, i.e., a poorer survival, we found that patients within the third tertile were also at a higher risk for a breast cancer-related death. To date, this has not been shown previously and the findings do not support our primary hypothesis. However, a similar pattern, with a u-shaped relationship, between levels of 25OHD and risk of subsequent prostate cancer has been found in our cohort [39]. Also, one previous study on 25OHD levels measured at diagnosis and overall mortality in postmenopausal breast cancer patients, showed the lowest mortality among patients within the second tertile [37]. Since most of the anti-carcinogenic effects of vitamin $\mathrm{D}$ seem to be mediated by the vitamin $\mathrm{D}$ receptor (VDR) [30], individual- or tumor-specific differences in VDR may be of importance.

\section{PTH and breast cancer}

We did not find any association between levels of PTH and breast cancer-specific mortality. Previous experimental studies have suggested that PTH may be associated with poor breast cancer survival due to carcinogenic and tumor promoting effects [13-16], such as regulating angiogenesis and osteoclastogenesis in bone metastasis by breast cancer cells [40]. Therefore, our hypothesis was that there would be an association. Due to intra-individual variation of PTH levels [41, 42], there is a risk of misclassification, which might have affected our results. There are no previous results reported from epidemiological studies on PTH and breast cancer survival, and our explorative analysis is the first within the area.

\section{Calcium and breast cancer}

High levels of calcium at diagnosis of breast cancer have previously been associated with large tumors, and this may well be an effect of the tumor per se [43]. Previous findings suggest an increased incidence and more aggressive breast cancer tumor characteristics, associated with higher prediagnostic calcium levels [7, 21, 44]. In contrast, our explorative analysis found an association between high prediagnostic levels of calcium and a lower breast cancer-specific mortality. This finding needs further scientific attention, and 
the expression or activity of the calcium receptor may modulate the effect of calcium on breast tumors.

\section{Methodological issues}

This study was performed using blood samples taken before diagnosis. Therefore, the tumor itself cannot have influenced the analyzed levels. The sensitivity analysis excluding women diagnosed within 2 years from baseline showed similar results regarding 25OHD and mortality from breast cancer, but statistical significance was lost in the upper tertile, assumingly due to loss of statistical power with a decreasing number of outcomes, more precisely 94 deaths from breast cancer instead of 113 .

It must be considered that there is only one blood sample available for analysis, sometimes taken many years before diagnosis, and it is possible that this sample does not reflect the individuals' habitual vitamin D, PTH and calcium status. Previous studies have shown, though, that 25OHD measured at two times, several years apart have a high correlation [45, 46].

Regarding PTH, it has been shown that there is a short-term (up to 6 weeks) intra-individual variation of about $25 \%$ [41, 42]. PTH also shows a relatively large circadian fluctuation [41], and the time of the day for blood donation in the present study has not been recorded [7]. Therefore, there is a risk of misclassification of PTH levels that may have attenuated a potential possibly obscure true association between pre-diagnostic levels of PTH and mortality from breast cancer. Contrary to PTH, total serum calcium has been shown to have a low intraindividual variation over short as well as long time [47, 48].

Vitamin D levels tend to decrease with increasing age, whereas PTH and calcium increases $[49,50]$. Therefore, we adjusted our analyses for age. We decided not to adjust for menopause in our analysis, as menopause is heavily dependent on age. In a sensitivity analysis, where we stratified for menopause, the analysis showed similar associations for postmenopausal women, but the analysis was unstable regarding premenopausal women, due to small numbers $(n=65)$ in this group.

Another factor that is known to affect serum levels of $25(\mathrm{OH}) \mathrm{D}$ is season [51], but as this factor was included in the multivariate analysis, we consider that such variation ought to have affected our results only to a minor extent.

Since all Swedish residents are given a unique civil registration number, it is possible to link all women to different registries. The Swedish Cause of Death Registry that was used to retrieve information on cause of death, had a coverage of $97.3 \%$ in 2008 [52], and it has been shown to be correct in $90 \%$ of cases where malignant tumors is the cause of death [53]. Therefore, it is expected that data concerning cause of death is complete and correct to a great extent.
As it has been previously shown that women within the MDCS cohort have a higher incidence of breast cancer, but lower breast cancer mortality, than non-participants, there is a risk of a selection bias. The mortality risk between participants in this study group and general population of Malmö, hence, may differ. However, as there was a broad distribution of 25OHD, and to some extent PTH in our material, we consider that relative risks were less likely to have been affected by a potential selection bias.

Primarily, we chose not to adjust for BMI in this study, since previous studies have shown that a high BMI is associated with low levels of vitamin D [54], and high BMI is also associated with a poor prognosis [55]; hence, it may be part of the casual pathway. A previous study has suggested the possibility of trapping vitamin D in subcutaneous fat [56]. Therefore, an adjustment for BMI could possibly have masked an association between vitamin $\mathrm{D}$ levels and breast cancer prognosis. When we stratified the analyses for normal versus overweight, we noted that associations were stronger in the overweight group compared to normal weight, which could be explained by the above reasoning.

Since the analysis was adjusted for prognostic factors that are used when deciding on adjuvant treatment, we chose to present the analyses not adjusting for treatment as this may have lead to an over-adjustment. Moreover, the sensitivity analysis that included treatment showed similar results as the main analysis.

Apart from the variables adjusted for in the present analyses, there may have been other factors of interest, such as information on human epidermal growth factor receptor 2 (HER-2), which is a known prognostic factor that influences both choice of treatment as well as prognosis of a diagnosed breast cancer. Unfortunately many tumors in our material were diagnosed before HER-2 was recognized and used in clinical practice.

Fortunately, breast cancer-specific mortality is relatively low, but this means few deaths from breast cancer in the present study. Nonetheless, we were able to find statistically significant data to support that pre-diagnostic 25OHD levels influence mortality from breast cancer. In this analysis, we could not find statistically significant associations between pre-diagnostic levels of PTH and breast cancer survival and also the association between levels of calcium and breast cancer mortality was weak. Since outcome, i.e., deaths from breast cancer are sparse, there is a possibility of type II error and true associations could have been missed.

\section{Conclusion}

Women with pre-diagnostic 25OHD levels within the first and third tertiles as compared to the second have a higher breast cancer-specific mortality, i.e., a poor survival. There 
was no association between pre-diagnostic levels of PTH and breast cancer mortality. A weak association was seen between high levels of pre-diagnostic calcium and low breast cancer mortality. Our analysis suggests that vitamin D levels may affect breast cancer survival, but that both low and relatively high levels may have an adverse effect.

Acknowledgments This work was supported by The Swedish Cancer Society, The Gunnar Nilsson Cancer Foundation, The Ernhold Lundström Foundation, The Henning and Ida Persson Foundation, The Einar and Inga Nilsson Foundation, The Malmö University Hospital Cancer Research Fund, The Skåne University Hospital Funds and Donations, The Breast Cancer network at Lund University
(BCLU), and The Region Skåne (ALF). The authors want to thank Dr Lola Anagnostaki, for pathologically examining all tumors diagnosed between 1991-2004, and RN Anna Hwasser for data management.

Open Access This article is distributed under the terms of the Creative Commons Attribution License which permits any use, distribution, and reproduction in any medium, provided the original author(s) and the source are credited.

\section{Appendix}

See Table 4.
Table 4 Tertiles of vitamin D3 in relation to age and breast cancer characteristics

\begin{tabular}{|c|c|c|c|c|c|}
\hline \multirow[t]{3}{*}{ Factor } & \multicolumn{5}{|c|}{ Tertile of D3 } \\
\hline & $\begin{array}{l}1 \mathrm{st} \leq 75 \\
(n=221)\end{array}$ & $\begin{array}{l}\text { 2nd 76-99 } \\
(n=216)\end{array}$ & $\begin{array}{l}3 \mathrm{rd} \geq 100 \\
(n=218)\end{array}$ & $\begin{array}{l}\text { Unknown } \\
(n=17)\end{array}$ & $\begin{array}{l}\text { Total } \\
(n=672)\end{array}$ \\
\hline & \multicolumn{5}{|c|}{ Column percent (mean and SD in italics) } \\
\hline \multicolumn{6}{|c|}{ Age at diagnosis (years) } \\
\hline Mean & 63.6 & 64.9 & 63.8 & 67.0 & 64.2 \\
\hline SD & 7.8 & 7.8 & 8.0 & 8.8 & 7.9 \\
\hline \multicolumn{6}{|l|}{ Size } \\
\hline $1-10 \mathrm{~mm}$ & 24 & 29 & 28 & 18 & 27 \\
\hline $11-20 \mathrm{~mm}$ & 48 & 42 & 42 & 59 & 44 \\
\hline$\geq 21 \mathrm{~mm}$ & 27 & 26 & 28 & 24 & 27 \\
\hline Unknown & 2 & 3 & 2 & 0 & 2 \\
\hline \multicolumn{6}{|c|}{ Lymph node status } \\
\hline Positive & 28 & 31 & 32 & 35 & 30 \\
\hline Negative & 71 & 68 & 67 & 65 & 69 \\
\hline Unknown & 1 & 1 & 1 & 0 & 1 \\
\hline \multicolumn{6}{|c|}{ Distant metastasis } \\
\hline Yes & 1 & 1 & 2 & 0 & 1 \\
\hline No & 99 & 99 & 98 & 100 & 98 \\
\hline Unknown & 1 & 1 & 0 & 0 & 0 \\
\hline \multicolumn{6}{|c|}{ Nottingham grade } \\
\hline I & 25 & 30 & 22 & 47 & 26 \\
\hline II & 43 & 43 & 46 & 41 & 44 \\
\hline III & 24 & 20 & 25 & 6 & 23 \\
\hline Unknown & 8 & 7 & 7 & 6 & 7 \\
\hline \multicolumn{6}{|c|}{ Histological type } \\
\hline Ductal & 68 & 67 & 63 & 71 & 66 \\
\hline Lobular & 19 & 17 & 21 & 24 & 19 \\
\hline Other/mixed & 6 & 12 & 9 & 0 & 9 \\
\hline Unknown & 7 & 5 & 7 & 6 & 6 \\
\hline \multicolumn{6}{|l|}{ ER } \\
\hline $0-10 \%$ pos & 12 & 8 & 12 & 6 & 11 \\
\hline$>10 \%$ pos & 72 & 74 & 73 & 71 & 73 \\
\hline Unknown & 16 & 18 & 16 & 24 & 17 \\
\hline \multicolumn{6}{|l|}{$\operatorname{PgR}$} \\
\hline $0-10 \%$ pos & 43 & 33 & 40 & 35 & 39 \\
\hline$>10 \%$ pos & 33 & 39 & 33 & 41 & 35 \\
\hline Unknown & 24 & 28 & 27 & 24 & 26 \\
\hline
\end{tabular}




\section{References}

1. Colston KW (2008) Vitamin D and breast cancer risk. Best Pract Res Clin Endocrinol Metab 22(4):587-599. doi:10.1016/j.beem. 2008.08.002

2. Rohan T (2007) Epidemiological studies of vitamin D and breast cancer. Nutr Rev 65(Supplement 1):80. doi:10.1301/nr.2007.aug. S80-S83

3. Grant WB (2010) An ecological study of cancer incidence and mortality rates in France with respect to latitude, an index for vitamin D production. Dermatoendocrinol 2(2):62-67. doi:10. 4161/derm.2.2.13624

4. Chen W, Armstrong BK, Rahman B, Zheng R, Zhang S, Clements M (2013) Relationship between cancer survival and ambient ultraviolet B irradiance in China. Cancer Causes Control. doi:10.1007/s10552-013-0210-4

5. Robsahm TE, Tretli S, Dahlback A, Moan J (2004) Vitamin D3 from sunlight may improve the prognosis of breast-, colon- and prostate cancer (Norway). Cancer Causes Control 15(2):149-158. doi:10.1023/B:CACO.0000019494.34403.09

6. Porojnicu A, Robsahm TE, Berg JP, Moan J (2007) Season of diagnosis is a predictor of cancer survival. Sun-induced vitamin D may be involved: a possible role of sun-induced Vitamin D. J Steroid Biochem Mol Biol 103(3-5):675-678. doi:10.1016/j. jsbmb.2006.12.031

7. Almquist M, Bondeson AG, Bondeson L, Malm J, Manjer J (2010) Serum levels of vitamin D, PTH and calcium and breast cancer risk-a prospective nested case-control study. Int J Cancer 127(9):2159-2168. doi:10.1002/ijc.25215

8. Gorham ED, Mohr SB, Garland FC, Garland CF (2009) Vitamin D for cancer prevention and survival. Clin Rev Bone Miner Metab 7(2):159-175. doi:10.1007/s12018-009-9028-8

9. Shao T, Klein P, Grossbard ML (2012) Vitamin D and breast cancer. Oncologist 17(1):36-45. doi:10.1634/theoncologist.2011-0278

10. Rose AA, Elser C, Ennis M, Goodwin PJ (2013) Blood levels of vitamin D and early stage breast cancer prognosis: a systematic review and meta-analysis. Breast Cancer Res Treat 141(3):331-339. doi:10.1007/s10549-013-2713-9

11. Freedman DM, Looker AC, Chang SC, Graubard BI (2007) Prospective study of serum vitamin D and cancer mortality in the United States. J Natl Cancer Inst 99(21):1594-1602. doi:10.1093/ jnci/djm204

12. Steingrimsdottir L, Gunnarsson O, Indridason OS, Franzson L, Sigurdsson G (2005) Relationship between serum parathyroid hormone levels, vitamin D sufficiency, and calcium intake. JAMA 294(18):2336-2341. doi:10.1001/jama.294.18.2336

13. Linforth R, Anderson N, Hoey R, Nolan T, Downey S, Brady G, Ashcroft L, Bundred N (2002) Coexpression of parathyroid hormone related protein and its receptor in early breast cancer predicts poor patient survival. Clinical Cancer 8(10):3172-3177

14. Hoey RP, Sanderson C, Iddon J, Brady G, Bundred NJ, Anderson NG (2003) The parathyroid hormone-related protein receptor is expressed in breast cancer bone metastases and promotes autocrine proliferation in breast carcinoma cells. $\mathrm{Br} \mathrm{J}$ Cancer 88(4):567-573. doi:10.1038/sj.bjc.6600757

15. Birch MA, Carron JA, Scott M, Fraser WD, Gallagher JA (1995) Parathyroid hormone (PTH)/PTH-related protein (PTHrP) receptor expression and mitogenic responses in human breast cancer cell lines. Br J Cancer 72(1):90-95

16. Cataisson C, Lieberherr M, Cros M, Gauville C, Graulet AM, Cotton J, Calvo F, de Vernejoul MC, Foley J, Bouizar Z (2000) Parathyroid hormone-related peptide stimulates proliferation of highly tumorigenic human SV40-immortalized breast epithelial cells. J Bone Miner 15(11):2129-2139. doi:10.1359/jbmr.2000. 15.11.2129
17. Palmer M, Adami HO, Krusemo UB, Ljunghall S (1988) Increased risk of malignant diseases after surgery for primary hyperparathyroidism. A nationwide cohort study. Am J Epidemiol 127(5):1031-1040

18. Michels KB, Xue F, Brandt L, Ekbom A (2004) Hyperparathyroidism and subsequent incidence of breast cancer. Int $\mathrm{J}$ Cancer 110(3):449-451. doi:10.1002/ijc.20155

19. Nilsson IL, Zedenius J, Yin L, Ekbom A (2007) The association between primary hyperparathyroidism and malignancy: nationwide cohort analysis on cancer incidence after parathyroidectomy. Endocr Relat Cancer 14(1):135-140. doi:10.1677/erc.1. 01261

20. Pickard AL, Gridley G, Mellemkjae L, Johansen C, KofoedEnevoldsen A, Cantor KP, Brinton LA (2002) Hyperparathyroidism and subsequent cancer risk in Denmark. Cancer 95(8):1611-1617. doi:10.1002/cncr.10846

21. Almquist M, Manjer J, Bondeson L, Bondeson A-G (2007) Serum calcium and breast cancer risk: results from a prospective cohort study of 7,847 women. Cancer Causes Control 18(6):595-602. doi:10.1007/s10552-007-9001-0

22. Ramasamy I (2006) Recent advances in physiological calcium homeostasis. Clin Chem Lab Med 44(3):237-273. doi:10.1515/ CCLM.2006.046

23. Manjer J, Carlsson S, Elmstahl S, Gullberg B, Janzon L, Lindstrom M, Mattisson I, Berglund G (2001) The Malmo Diet and Cancer Study: representativity, cancer incidence and mortality in participants and non-participants. Eur $\mathrm{J}$ Cancer Prev 10(6):489-499

24. Butt S (2011) Reproductive factors and breast cancer-parity, breastfeeding and genetic predisposition in relation to risk and prognosis. Lund University, Faculty of Medicine Doctoral Dissertation Series, 10

25. Borgquist S, Anagnostaki L, Jirstrom K, Landberg G, Manjer J (2007) Breast tumours following combined hormone replacement therapy express favourable prognostic factors. Int $\mathrm{J}$ Cancer 120(10):2202-2207. doi:10.1002/ijc. 22542

26. Wallström P, Department of Clinical Sciences M, Lund U, Emergency mMS, Internal M, Lunds u, Institutionen för kliniska vetenskaper M, Faculty of M, Medicin, Sektionen för AMK (2002) Diet, lifestyle, antioxidants, and biomarkers of cancer risk: an epidemiological report from the Malmö Diet and Cancer cohort. Dissertation/Thesis, Univ.-sjukhuset MAS, Malmö

27. Anker P, Wieland E, Ammann D, Dohner RE, Asper R, Simon W (1981) Neutral carrier based ion-selective electrode for the determination of total calcium in blood serum. Anal Chem 53(13):1970-1974

28. Gross M, Kost SB, Ennis B, Stumpf W, Kumar R (1986) Effect of 1,25-dihydroxyvitamin D3 on mouse mammary tumor (GR) cells: evidence for receptors, cellular uptake, inhibition of growth and alteration in morphology at physiologic concentrations of hormone. J Bone Miner Res 1(5):457-467. doi:10.1002/jbmr.5650010510

29. Simboli-Campbell M, Gagnon A, Franks DJ, Welsh J (1994) 1,25-Dihydroxyvitamin D3 translocates protein kinase $\mathrm{C}$ beta to nucleus and enhances plasma membrane association of protein kinase $\mathrm{C}$ alpha in renal epithelial cells. J Biol Chem 269(5):3257-3264

30. Fleet JC, DeSmet M, Johnson R, Li Y (2012) Vitamin D and cancer: a review of molecular mechanisms. Biochem $\mathrm{J}$ 441(1):61-76. doi:10.1042/BJ20110744

31. Leyssens C, Verlinden L, Verstuyf A (2013) Antineoplastic effects of 1,25(OH)2D3 and its analogs in breast, prostate and colorectal cancer. Endocr Relat Cancer 20(2):R31-R47. doi:10. 1530/erc-12-0381

32. Grant WB, Peiris AN (2012) Differences in vitamin D status may account for unexplained disparities in cancer survival rates 
between African and white Americans. Dermatoendocrinol 4(2):85-94. doi:10.4161/derm.19667

33. Goodwin PJ, Ennis M, Pritchard KI, Koo J, Hood N (2009) Prognostic effects of 25-hydroxyvitamin D levels in early breast cancer. J Clin Oncol 27(23):3757-3763. doi:10.1200/JCO.2008. 20.0725

34. Tretli S, Schwartz GG, Torjesen PA, Robsahm TE (2012) Serum levels of 25-hydroxyvitamin D and survival in Norwegian patients with cancer of breast, colon, lung, and lymphoma: a population-based study. Cancer Causes Control 23(2):363-370. doi:10.1007/s10552-011-9885-6

35. Hatse S, Lambrechts D, Verstuyf A, Smeets A, Brouwers B, Vandorpe T, Brouckaert O, Peuteman G, Laenen A, Verlinden L, Kriebitzsch C, Dieudonne AS, Paridaens R, Neven P, Christiaens MR, Bouillon R, Wildiers H (2012) Vitamin D status at breast cancer diagnosis: correlation with tumor characteristics, disease outcome, and genetic determinants of vitamin D insufficiency. Carcinogenesis 33(7):1319-1326. doi:10.1093/carcin/bgs187

36. Villasenor A, Ballard-Barbash R, Ambs A, Bernstein L, Baumgartner K, Baumgartner R, Ulrich CM, Hollis BW, McTiernan A, Neuhouser ML (2013) Associations of serum 25-hydroxyvitamin $\mathrm{D}$ with overall and breast cancer-specific mortality in a multiethnic cohort of breast cancer survivors. Cancer Causes Control 24(4):759-767. doi:10.1007/s10552-013-0158-4

37. Vrieling A, Hein R, Abbas S, Schneeweiss A, Flesch-Janys D, Chang-Claude J (2011) Serum 25-hydroxyvitamin D and postmenopausal breast cancer survival: a prospective patient cohort study. Breast Cancer Res 13(4):R74. doi:10.1186/bcr2920

38. Ross AC, Manson JE, Abrams SA, Aloia JF, Brannon PM, Clinton SK, Durazo-Arvizu RA, Gallagher JC, Gallo RL, Jones G, Kovacs CS, Mayne ST, Rosen CJ, Shapses SA (2011) The 2011 report on dietary reference intakes for calcium and vitamin $\mathrm{D}$ from the Institute of Medicine: what clinicians need to know. J Clin Endocrinol Metab 96(1):53-58. doi:10.1210/jc.2010-2704

39. Brandstedt J, Almquist M, Manjer J, Malm J (2012) Vitamin D, PTH, and calcium and the risk of prostate cancer: a prospective nested case-control study. Cancer Causes Control 23(8):1377-1385. doi:10.1007/s10552-012-9948-3

40. Isowa S, Shimo T, Ibaragi S, Kurio N, Okui T, Matsubara K, Hassan NM, Kishimoto K, Sasaki A (2010) PTHrP regulates angiogenesis and bone resorption via VEGF expression. Anticancer Res 30(7):2755-2767

41. Ankrah-Tetteh T, Wijeratne S, Swaminathan R (2008) Intraindividual variation in serum thyroid hormones, parathyroid hormone and insulin-like growth factor-1. Ann Clin Biochem 45(Pt 2):167-169. doi:10.1258/acb.2007.007103

42. Viljoen A, Singh DK, Twomey PJ, Farrington K (2008) Analytical quality goals for parathyroid hormone based on biological variation. Clin Chem Lab Med 46(10):1438-1442. doi:10.1515/ CCLM.2008.275

43. Thaw SS, Sahmoun A, Schwartz GG (2012) Serum calcium, tumor size, and hormone receptor status in women with untreated breast cancer. Cancer Biol Ther 13(7):467-471. doi:10.4161/cbt. 19606

44. Almquist M, Anagnostaki L, Bondeson L, Bondeson AG, Borgquist S, Landberg G, Malina J, Malm J, Manjer J (2009) Serum calcium and tumour aggressiveness in breast cancer: a prospective study of 7847 women. Eur J Cancer Prev 18(5):354-360. doi:10.1097/CEJ.0b013e32832c386f

45. Meng JE, Hovey KM, Wactawski-Wende J, Andrews CA, Lamonte MJ, Horst RL, Genco RJ, Millen AE (2012) Intraindividual variation in plasma 25-hydroxyvitamin $\mathrm{D}$ measures 5 years apart among postmenopausal women. Cancer Epidemiol Biomarkers Prev 21(6):916-924. doi:10.1158/1055-9965.EPI-120026

46. Platz EA, Leitzmann MF, Hollis BW, Willett WC, Giovannucci E (2004) Plasma 1,25-dihydroxy- and 25-hydroxyvitamin D and subsequent risk of prostate cancer. Cancer Causes Control 15(3):255-265. doi:10.1023/B:CACO.0000024245.24880.8a

47. Gallagher SK, Johnson LK, Milne DB (1989) Short-term and long-term variability of indices related to nutritional status. I: Ca, $\mathrm{Cu}, \mathrm{Fe}, \mathrm{Mg}$, and $\mathrm{Zn}$. Clin Chem 35(3):369-373

48. Ricos C, Alvarez V, Cava F, Garcia-Lario JV, Hernandez A, Jimenez CV, Minchinela J, Perich C, Simon M (1999) Current databases on biological variation: pros, cons and progress. Scand J Clin Lab Invest 59(7):491-500

49. Lips P (2006) Vitamin D physiology. Prog Biophys Mol Biol 92(1):4-8. doi:10.1016/j.pbiomolbio.2006.02.016

50. Need AG, O'Loughlin PD, Morris HA, Horowitz M, Nordin BE (2004) The effects of age and other variables on serum parathyroid hormone in postmenopausal women attending an osteoporosis center. J Clin Endocrinol Metab 89(4):1646-1649

51. Lips P, van Schoor NM, de Jongh RT (2014) Diet, sun, and lifestyle as determinants of vitamin D status. Ann N Y Acad Sci. doi:10.1111/nyas. 12443

52. Welfare NBoHa (2010) Cause of death statistics; history, production and reliability (in Swedish). http://www.socialstyrelsen. se/publikationer2010/2010-4-33. Accessed 21 Dec 2013

53. Johansson LA, Bjorkenstam C, Westerling R (2009) Unexplained differences between hospital and mortality data indicated mistakes in death certification: an investigation of 1,094 deaths in Sweden during 1995. J Clin Epidemiol 62(11):1202-1209. doi:10.1016/j.jclinepi.2009.01.010

54. Brock K, Huang WY, Fraser DR, Ke L, Tseng M, StolzenbergSolomon R, Peters U, Ahn J, Purdue M, Mason RS, McCarty C, Ziegler RG, Graubard B (2010) Low vitamin D status is associated with physical inactivity, obesity and low vitamin D intake in a large US sample of healthy middle-aged men and women. J Steroid Biochem Mol Biol 121(1-2):462-466. doi:10.1016/j. jsbmb.2010.03.091

55. Pajares B, Pollan M, Martin M, Mackey JR, Lluch A, Gavila J, Vogel C, Ruiz-Borrego M, Calvo L, Pienkowski T, RodriguezLescure A, Segui MA, Tredan O, Anton A, Ramos M, Del Carmen M, Rodriguez-Martin C, Carrasco E, Alba E (2013) Obesity and survival in operable breast cancer patients treated with adjuvant anthracyclines and taxanes according to pathological subtypes: a pooled analysis. Breast Cancer Res 15(6):R105. doi: $10.1186 / \mathrm{bcr} 3572$

56. Wortsman J, Matsuoka LY, Chen TC, Lu Z, Holick MF (2000) Decreased bioavailability of vitamin D in obesity. Am J Clin Nutr 72(3):690-693 